\title{
Can US Wage Increases be Regarded as a Leading Indicator for Bond Rates?
}

\author{
Ekin Ayşe Özşuca ErenoĞLua Elif ÖZnur ACAR ${ }^{\mathrm{b}}$ \\ Received: 31.03.2020; Revised: 11.06.2020; Accepted: 15.06.2020
}

\begin{abstract}
After the subprime meltdown, the Federal Reserve focused its attention on US nonfarm payroll data in order to pave the way for its fund rate hikes. As time went by, the Federal Reserve deemed particularly one sub-component of this data, namely the increments on average weekly wage growth as a proxy for inflation and thus a plausible explanation for raising the interest rates. In that aspect, we decide to elaborate on this issue further and examine whether this implemented strategy indeed had a reflection in the real market. For doing so, we intend to determine whether there is any causality relation in either direction between US average weekly wage increases and 10-year Treasury Bond rates. We utilize the Toda-Yamamoto causality approach and come up with a statistically significant result between wages and bond rates. For robustness, we also consider the unemployment rate and consumption expenditures as independent variables.
\end{abstract}

JEL codes: E24, C58, G12

Keywords: Wage increases, Bond rates, Granger causality

\section{Introduction}

In the wake of the 2008 financial crisis and subsequent recession, The Federal Reserve (Fed) implemented a series of accommodative monetary policy measures to restore the economy and financial markets. The rate cuts, quantitative easing, forward guidance and several other tools were deployed against soaring unemployment rates, plummeting stock market and the downturn in economic activity. In its endeavor, the Fed pursued its dual statutory mandate of maximum employment and price stability.

As inflation rates consistently remained lower than the preset objectives in the early stages of the recession, the Fed focused its attention largely on the jobs market in its conduct of monetary policy. This shift of focus from the conventional use of price stability and economic growth to maximum employment in the Fed's policy objectives started in 2008 (Thornton, 2011; Steelman, 2011; Taylor, 2011). At her famous Jackson Hole speech in 2014, the governor Janet Yellen formally prioritized the role of the labor market conditions in monetary policy deliberations: "Federal Open Market Committee's (FOMC) view

\footnotetext{
a Corresponding author. Department of International Trade, Çankaya University, Ankara, Turkey. email: aozsuca@cankaya.edu.tr@ https://orcid.org/0000-0002-5615-3028

b Department of Economics, Çankaya University, Ankara, Turkey. email: elifoznurkan@cankaya.edu.tr(D) https://orcid.org/0000-0002-3104-9013
} 
that policy decisions will not be based on any single indicator, but will instead take into account a wide range of information on the labor market, as well as inflation and financial developments".

In this regard, FOMC looks at a number of labor market indicators, including unemployment rate, labor force participation rate, nonfarm payroll employment, and employment to population ratio. The unemployment rate has historically been the leading indicator, given that the congressional decree is phrased in full employment terms. However, as Yellen elaborates, the unexpectedly swift fall in the unemployment rate from its record-high 10 percent levels since 2010 raised concern among policymakers over its ability in assessing the extent of remaining slack in the market, and the identification of cyclical versus structural effects of the recession. This was also confirmed by a considerable body of research suggesting that structural forces such as demographic trends like aging, sectoral shift of employment from manufacturing to services, and job polarization have considerably affected the labor market. In Yellen's words: "what begins as cyclical weaknesses may evolve into structural damages". The response was a reformulation of forward guidance to be based on not a single but a variety of labor market indicators.

Among several indicators (i.e. participation rate, involuntary part-time employment, private sector worker flows), labor compensation received particular interest. The subdued real wages growing less than labor productivity was assumed to point to a more realistic picture of market conditions than would be indicated by the unemployment rate. The Fed tried to explain the stagnant wage growth by three forces: (i) pent-up wage deflation which resulted from firms' inability to lower nominal wages during the early years of the recession and then finding it unnecessary to raise them in the following recovery period, (ii) changes in the share of labor income due to changing production and trade patterns which had predated the recession, (iii) impediments to cyclically dislocated workers' re-employment in the recovered stronger economy pushing down wages. Given these unprecedented aspects of the Great Recession and its recovery, the lead-lag relationship between labor cost inflation and price inflation has become both more nuanced and complex for monetary policy deliberations. Nonetheless, the Phillips curve paradigm prioritizing an accurate assessment of wage growth as a key factor in forecasting policy changes is still-widely accepted in the eyes of the FOMC and the private sector, and the average weekly wages series released every month stand among the most-watched of all wage indicators.

As wages, in this way, became the defining feature of the monetary policy, financial markets, in turn, started to react ever-increasingly to wages for shaping the expectations. In what follows, the precursory relationship between the US wages and stock returns (see, for instance, İlalan (2018)), interest rates, bond yields, etc. is becoming a popular topic. However, one should note that despite the vast literature of wages, the literature regarding the relationship between US average weekly wage increases and other macroeconomic variables is extremely shallow due to its recency. In that aspect, this study investigates whether there exists such a relationship between the US average weekly wage increases and 10-year US Treasury bond yields. We particularly consider the long-term bond yields based on the premise that economic theory, despite widely assuming that the central banks' policy rates have an impact on both intermediate and long-term interest rates, asserts that the central banks' ability to control interest rate fluctuations is not unlimited. The central banks do not have absolute power on market interest rates, as policy rate cuts may only be transmitted partially to long term yields (Ball et al., 2016). Based on this presumption and the existing 
evidence, we use 10-year Treasury bond yields as our proxy measure for the market's reaction to monetary policy. Our particular choice of 10-year maturity Treasury bonds relies on the fact that it is conventionally deemed as the basic indicator for interest rates throughout the world. It is evident that the US 10-year T-bond rate is the main indicator not only for world bond and foreign exchange markets but also for global stock indices. As mentioned by Özel \& İlalan (2018) and İlalan \& Özel (2019) mean-reversion thus predictability of bond yields alters the decision of portfolio managers in the sense that lower bond yields will trigger a flow to stocks. To the best of our knowledge, this study is the first attempt in the literature to test the existence and nature of the causality relation between the US average weekly wages and 10-year Treasury bonds.

In the empirical analysis, we use monthly data for the US average weekly wage growth and 10-year Treasury bond yields from January 2009 to April 2019. First, we test the stationarity of the variables applying Augmented Dickey-Fuller (ADF) (Dickey \& Fuller, 1979, 1981) and Phillips-Perron (PP) (Phillips \& Perron, 1988) unit root tests. Next, we apply Toda \& Yamamoto (1995) procedure to our series, which enables testing causality between series with different degrees of integration and avoids some shortcomings associated with the standard Granger (1969) causality test.

The paper is organized as follows. Section 2 sets out the data and methodology used. Section 3 presents the results of the causality relationship between the US average weekly wage increases and 10-year Treasury bonds yields. In addition, we check for robustness via taking unemployment rate and consumption expenditures. Finally, the last section concludes and discusses the avenues for future research.

\section{Data and Methodology}

The data set consists of the US average weekly wage increases and 10-year Treasury bond yields between January 2009 and April 2019. The data for the US average weekly wage increases and 10-year T-Bond rates are retrieved from the Fed St. Louis and Bloomberg respectively. Figure 1 displays the US average weekly wage increases (on the left axis) and 10-year T-bond rates (on the right axis).

The particular choice of January 2009 as the sample start year rests on a number of presumptions. Firstly, the subprime meltdown of 2007 in the United States inevitably contributed to building-up of financial imbalances, and hence major breakdowns in various markets in the fall of 2008, which resulted in the worst financial crisis of the post-World War II period and a subsequent severe economic recession. Thus, we opt for treating 2007 and 2008 as the period of the global financial downturn and focusing specifically on the postcrisis era. Second, there have been significant changes in the conduct of macroeconomic policymaking with the implementation of quantitative easing programs since the onset of the crisis. More importantly, the primary focus of the Fed to use wage increases as a proxy for inflation, and that they are regarded as a precursor for an increase in the Fed funds rate were nil until the global financial turmoil. Thus, in pursuit of a possible causal relationship between the US average weekly earnings and 10-year T-bond rates, the particular choice of this period becomes more evident. Last but not least, we seek to subsume rich series on both variables in order to mitigate the small sample bias in the econometric analysis.

The empirical analysis consists of two steps. Considering the widely accepted assumption in the literature that interest rates are non-stationary, we first carry out unit root tests to 


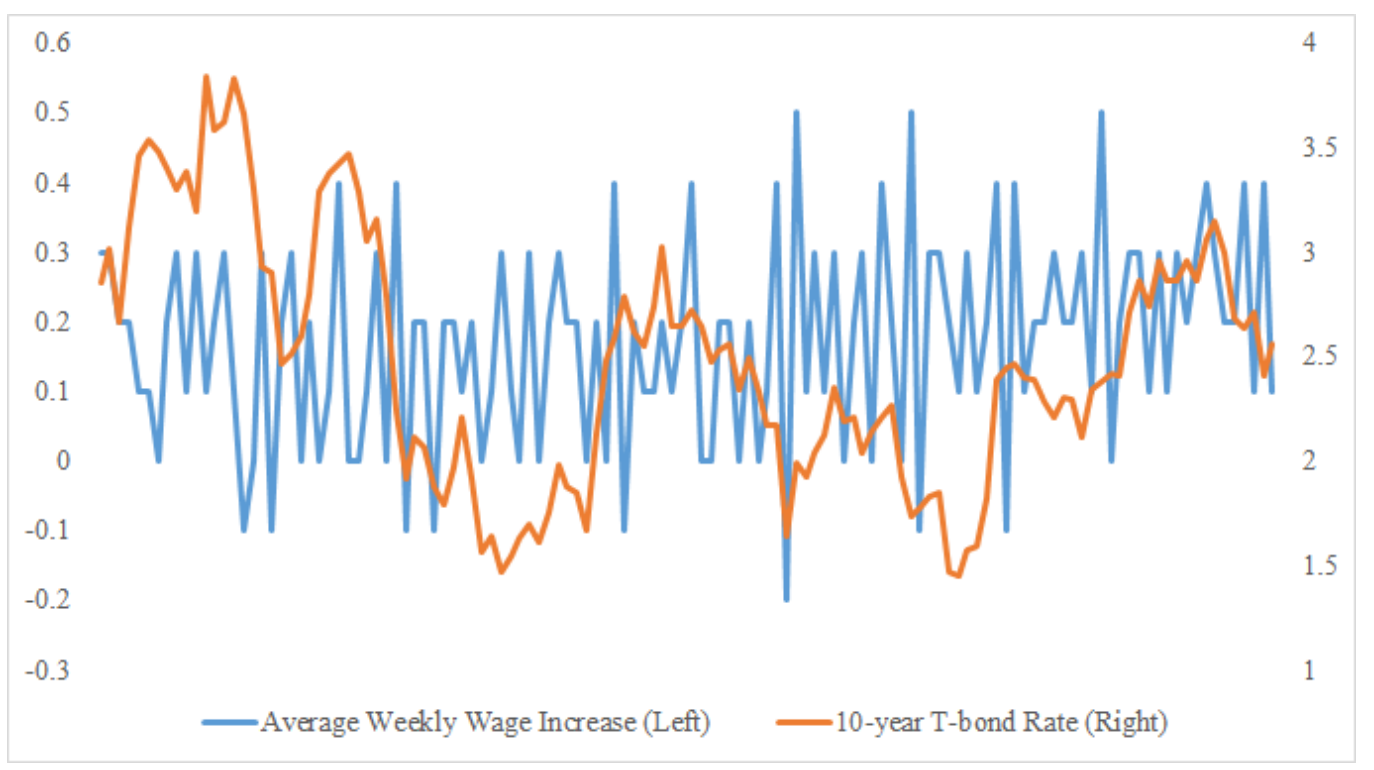

Figure 1: Wage increase and 10-year bond rates in the US Monthly data covering the period Jan. 2009 and Apr. 2019

identify whether the variable series are stationary or not. In that respect, we first apply the traditional ADF and PP tests to determine whether 10-year US Treasury bond rates possess a unit root. The results confirm that the interest rate series is not stationary and follows integrated processes. We then apply the same unit root tests to the average weekly earnings data and find that the series is stationary.

In the second step, we investigate the causality between US average weekly earnings and 10-year T-Bill rates following Toda \& Yamamoto (1995) procedure, which provides testing causality along with series with different degrees of integration, and avoids some shortcomings associated with the standard Granger (1969) causality test.

The VAR model developed by Granger (1969) requires a stationary time series in order to eliminate spurious regression in the causality test. This problem of non-stationarity is overcome through differencing the data until stationarity is achieved, but this could result in loss of information and long-term relationship while trying to explain causality. Besides, if the variables that are being analyzed reach stationarity on the same level, the relationship of co-integration must also be analyzed. While the Vector Error Correction Model (VECM) could be used where co-integration exists in relationships between variables, the VECM model becomes invalid when no co-integration exists. Therefore, the VAR and the VECM models are sensitive to preliminary preparation tests like the unit root and co-integration for determining the causal relationship between variables.

Toda \& Yamamoto (1995) have shown that even in cases of the variables not being stationary, the VAR model, where level values are present, could be assumed and that the modified WALD (MWALD) test could be applied. In the lag augmented VAR model developed by Toda \& Yamamoto (1995), the variables not being stationary at the level and any possible co-integration between the series no longer constitute a problem. In order for this method to be applied, it is necessary for the maximum degree of integration (dmax) to 
be smaller than the lag length $(k) .{ }^{1}$ For the Toda-Yamamoto causality test to be applied to the variables, several steps must be taken. In the Toda-Yamamoto analysis, the first step is to identify the maximum order of integration of the series $(d \max )$. In the second step, the most appropriate lag length $(k)$ for the identified VAR model is determined using information criteria such as Schwarz Information Criterion (SC) and Akaike Information Criterion (AIC). In the third step, the $(k+d \text { max })^{t h}$ order of the VAR model is estimated with seemingly unrelated regression. In the final step, the hypotheses are tested with the MWALD test, which has an asymptotic Chi square distribution, in order to determine the causal relationship between the variables studied. If the null hypothesis between the relevant variables is rejected, the causal relationship between the variables is validated.

\section{Results and Robustness Check}

As the principal aim of the study is to investigate causality between US average weekly earnings and 10-year government bond rates, it is vital to determine the order of integration before estimating causality. Accordingly, the stationarity results related to both variables through the application of ADF and PP root tests are presented in Table 1.

Table 1: Unit Root Tests

\begin{tabular}{|c|c|c|c|c|c|}
\hline & & & No trend, no constant & Constant, no trend & Trend, constant \\
\hline Wages & & $\begin{array}{c}\text { ADF } \\
\text { PP }\end{array}$ & $\begin{array}{c}0.7714 \\
-9.1173^{* * *}\end{array}$ & $\begin{array}{c}-0.0068 \\
-15.8617^{* * *}\end{array}$ & $\begin{array}{c}-2.708 \\
-19.6777^{* * *}\end{array}$ \\
\hline \multirow{2}{*}{ Bonds } & Level & $\begin{array}{l}\mathrm{ADF} \\
\mathrm{PP}\end{array}$ & $\begin{array}{l}-0.5946 \\
-0.6026\end{array}$ & $\begin{array}{l}-2.1108 \\
-2.2939\end{array}$ & $\begin{array}{l}-2.1221 \\
-2.3408\end{array}$ \\
\hline & $1^{\text {st }}$ diff. & $\begin{array}{l}\mathrm{ADF} \\
\mathrm{PP}\end{array}$ & $\begin{array}{l}-10.6338^{* * *} \\
-10.6361^{* * *}\end{array}$ & $\begin{array}{l}-10.5928^{* * *} \\
-10.5954^{* * *}\end{array}$ & $\begin{array}{l}-10.5634^{* * *} \\
-10.5662^{* * *}\end{array}$ \\
\hline
\end{tabular}

Since at least one of the series is integrated, we will be testing for Granger causality by using the Toda \& Yamamoto (1995) procedure as summarized in Section 2 .

Now we look for optimal lag lengths between US average weekly earnings and 10-year Treasury bond yields as VAR models are highly sensitive to the lag length of variables used in equations. Lag lengths are set according to two different criteria, namely SC and AIC. The optimal lags for both weekly earnings and 10-year T-bond rates have been identified to be 0 .

In order to preclude inefficiency issues, we have tested for the serial correlation of residuals. The results of the LM test for serial correlation are provided in Table 2. We can infer that there are no problematic cases for a significance level of $1 \%$. Therefore, we can easily take the optimal lag as 0 without any hesitation.

Table 2: Serial Correlation of the Residuals

\begin{tabular}{|lrc|llr|}
\hline Lag & LM-Stat & Prob. & Lag & LM-Stat & Prob. \\
\hline 1 & 4.807209 & 0.3077 & 5 & 6.608916 & 0.1581 \\
2 & 7.116928 & 0.1298 & 6 & 9.935917 & 0.0415 \\
3 & 12.47147 & 0.0142 & 7 & 1.631184 & 0.8032 \\
4 & 1.83409 & 0.7662 & 8 & 4.421386 & 0.352 \\
\hline
\end{tabular}

\footnotetext{
${ }^{1}$ For the relevant theoretical structure and discussion of the method, see, among others, Rambaldi (1997) and Zapata \& Rambaldi (1997).
} 
Now we can perform the Granger causality tests and the results are provided in Table 3. It is important to note that the causality test is applied by adding a lag that is based on the order of information, which the Toda-Yamamoto approach requires.

Table 3: Granger Causality Results

\begin{tabular}{|c|c|c|}
\hline Null Hypothesis & $\chi^{2}$ stat. & p-value \\
\hline US wage does not Granger cause US bond & 4.9079 & $0.0267^{* *}$ \\
\hline US bond does not Granger cause US wage & 2.2953 & 0.1298 \\
\hline
\end{tabular}

The results show that US average weekly wages Granger cause the 10-year Treasury bond yields with $5 \%$ significance level. However, the results do not provide any evidence of causation in the opposite direction.

In order to validate the findings related to Granger causality tests, we have applied the Johansen co-integration tests, while the results are presented in Table 4.

Table 4: Johansen Co-integration Test Results

\begin{tabular}{|lcc|}
\hline Hypothesized number & Trace stat. & p-value \\
\hline None & 32.9118 & $0.0001^{* * *}$ \\
At most 1 & 5.0411 & $0.0247^{* *}$ \\
\hline
\end{tabular}

Note: ${ }^{* * *},{ }^{* *},{ }^{*}$ denote statistical significance at 1\%, $5 \%$ and $10 \%$ levels, respectively.

To check for robustness, our first attempt is to determine whether the rank of cointegrating vectors is consistent. This is done by splitting the series into two sub-samples and the results are displayed in Table 5 .

Table 5: Johansen Co-integration Test Results for Sub-samples

\begin{tabular}{|llcc|}
\hline Sample & Hypothesized number & Trace stat. & p-value \\
\hline \multirow{2}{*}{ Sub-sample 1 } & None & 31.9416 & $0.0001^{* * *}$ \\
& At most 1 & 2.7464 & $0.0975^{*}$ \\
\hline \multirow{2}{*}{ Sub-sample 2 } & None & 18.2150 & $0.0190^{* *}$ \\
& At most 1 & 3.0190 & $0.0823^{*}$ \\
\hline
\end{tabular}

Note: ***, **** denote statistical significance at 1\%, 5\% and 10\% levels, respectively.

In addition, we seek for possible alternative factors that may have affected the causality relationship. In that respect, we took US personal consumption expenditures (PCE), unemployment rate and consumer price index (CPI).

Table 6: Granger Causality Results

\begin{tabular}{|lcc|}
\hline Null Hypothesis & $\chi^{2}$ stat. & p-value \\
\hline US PCE does not Granger US bond & 0.1232 & 0.9403 \\
US bond does not Granger cause US PCE & 1.2091 & 0.5463 \\
US unemployment rate does not Granger US bond & 1.1463 & 0.2843 \\
US bond does not Granger cause US unemployment rate & 0.8255 & 0.3636 \\
US PCI does not Granger US bond & 0.6398 & 0.7262 \\
US bond does not Granger cause US PCI & 4.1115 & 0.1280 \\
\hline
\end{tabular}

Note: ${ }^{* * *},{ }^{* *},{ }^{*}$ denote statistical significance at $1 \%, 5 \%$ and $10 \%$ levels, respectively. 
We could not achieve any significant causality relation in either direction as shown in Table 6 . For the sake of brevity, we have not displayed the detailed analysis which comprises the Toda-Yamamoto approach as done in the previous section.

\section{Conclusion}

Following the 2008 financial crisis and subsequent recession, the Fed reformulated its forward guidance and prioritized the role of the job market in monetary policy deliberations. Among several labor market indicators from the historically leading unemployment rate to labor force participation rates, average weekly wages became the most pronounced and watched in the eyes of both the FOMC and the financial markets. Consequently, the effects of the wages in the financial markets as a precursor received substantial interest in the empirical literature. In this study, we further elaborate on this issue by taking up the relationship between US average weekly wages and 10-year Treasury bond yields. More specifically, we try to understand whether US average weekly wages, which are taken as the leading indicators of the Fed funds rates, do exert a similar prominent effect on the dynamics of the financial markets.

Using data for the January 2009-April 2019 period, we first test the stationarity of the variables, determine the order of integration and then apply Toda \& Yamamoto (1995) procedure for causality. The results display that the US average weekly wages Granger cause the 10-year Treasury bond yields, but not vice versa. That is, the financial markets indeed strongly react to and returns are realized according to the wage growth indicator pinpointed by the Fed. For robustness check, we performed a similar causality analysis for the historically leading labor market indicator - unemployment rate and could not find such a one-way Granger causality relationship. In words, the unemployment rate figures that are now discarded by the Fed in its monetary policy have no significant predictive effect on the financial markets. Similarly, other long-standing leading indicators of monetary policy, i.e. US personal consumption expenditures (PCE) and consumer price index (CPI), do not display any significant causality relation in either direction. As a conclusion, an investor can allocate his/her portfolio between stocks and bonds through considering wage increases since we demonstrate a significant causality relation between wage increases and bond yields.

\section{References}

Ball, L., Gagnon, J., Honohan, P., \& Krogstrup, S. (2016). What Else Can Central Banks Do? (Geneva Reports on the World Economy No. 18). The International Center for Monetary and Banking Studies.

Dickey, D. A., \& Fuller, W. A. (1979). Distribution of the Estimators for Autoregressive Time Series with a Unit Root. Journal of the American Statistical Association, 74(366), 427-31. doi:10.2307/2286348

Dickey, D. A., \& Fuller, W. A. (1981). Likelihood Ratio Statistics for Autoregressive Time Series with a Unit Root. Econometrica, 49(4), 1057-72. doi:10.2307/1912517

Granger, C. W. J. (1969). Investigating Causal Relations by Econometric Models and Cross-spectral Methods. Econometrica, 37(3), 424-38. doi:10.2307/1912791 
İlalan, D. (2018). How US Wages Effect Post-socialist European Stock Markets: An Empirical Study. Economics and Business Letters, 7(4), 180-89. doi:10.17811/ebl.7.4.2018.179188

İlalan, D., \& Özel, Ö. (2019). Unit Root Testing in the Presence of Mean Reverting Jumps: Evidence from US T-Bond Yields. International Journal of Nonlinear Sciences and Numerical Simulation, 20(1), 145-52. doi:10.1515/ijnsns-2018-0012

Özel, Ö., \& İlalan, D. (2018). An Alternative Mean Reversion Test for Interest Rates. Central Bank Review, 7(1), 35-39. doi:10.1016/j.cbrev.2017.12.001

Phillips, P. C., \& Perron, P. (1988). Testing for a Unit Root in Time Series Regression. Biometrika, 75 (2), 335-46. doi:10.1093/biomet/75.2.335

Rambaldi, A. N. (1997). Multiple Time Series Models and Testing for Causality and Exogeneity: A Review (Working Papers in Econometrics and Applied Statistics No. 96). Department of Econometrics, University of New England, Australia.

Steelman, A. (2011). The Federal Reserve's 'dual mandate': The Evolution of an Idea (Economic Brief No. EB11-12). https://www.richmondfed.org/-/media/richmondfedorg/ publications/research/economic_brief/2011/pdf/eb_11-12.pdf.

Taylor, J. B. (2011). End the Fed's Dual Mandate and Focus on Prices. https://www.bloomberg.com/opinion/articles/2011-09-16/end-the-fed-s-dual -mandate-and-focus-on-prices-john-b-taylor.

Thornton, D. L. (2011). What Does the Change in the FOMC's Statement of Objectives Mean? Economic Synopses, 2011. doi:10.20955/es.2011.1

Toda, H. Y., \& Yamamoto, T. (1995). Statistical Inferences in Vector Autoregressions with Possibly Integrated Processes. Journal of Econometrics, 66(1-2), 225-50. doi:10.1016/0304-4076(94)01616-8

Zapata, H. O., \& Rambaldi, A. N. (1997). Monte Carlo Evidence On Cointegration and Causation. Oxford Bulletin of Economics and Statistics, 59(2), 285-98. doi:10.1111/14680084.00065 